\title{
Renovation of Research and Education in South Asian Countries by Means of ICT
}

\section{S. Ozawa1, D. D. G. L. Dahanayaka ${ }^{2 *}$, N. Warnajith ${ }^{3}$ and S. B. Quarmal ${ }^{4}$}

${ }^{1}$ Graduate School of Science and Engineering, Ibaraki University, 412-1Nakanarusawa, Hitachi 316-8511, Japan

${ }^{2}$ Department of Zoology, Faculty of Natural Sciences, The Open University of Sri Lanka, Nawala, Nugegoda, 10250, Sri Lanka

${ }^{3}$ Department of Computer Science, Faculty of Applied Science, University of Sri Jayewardenepura, Nugegoda, Sri Lanka

${ }^{4}$ Department of Media Studies \& Journalism, University of Liberal Arts Bangladesh, Dhanmondi, Dhaka-1209, Bangladesh

\section{Abstract}

Human resources are one of the most important factors for industrialization of developing countries. This is true especially for highly populated countries in South Asia. The point is the quality of education and how efficiently the education sectors provide the society with high quality workers. At present, rapid increase of demands for higher education can be seen in these countries. This is a remarkable trend because the production of well-educated people is the starting point of modernization of industries. E-learning can be considered as an efficient education system for knowledge sharing in developing countries. This paper discusses the present status of the higher education system in South Asia on the basis of the results of KISSEL (Knowledge Integration Servers System for E-learning) project that has been carried out by the authors in the last ten years. Further, the paper reviews the state of application of KISSEL and illustrates its relevance in renovation of research and education in South Asian Countries. The discussion addresses some future problems that can be solved with the aid of E-learning and E-research techniques. The second phase of the KISSEL project is also noted

\footnotetext{
*Correspondence should be addressed to D. D. G. L. Dahanayaka.
} Email: dddah@ou.ac.lk

https://orcid.org/0000-0001-9052-3873

(Received 09th September 2017; Revised 22nd October 2017; Accepted 02 ${ }^{\text {nd }}$ November 2017) (C) OUSL 
in relation to the future problems. In particular, development of new mobile application technique would be important for solving various local and transnational problems in South Asian countries.

Keywords: E-Learning, E-research, ICT, KISSEL, South Asia

\section{Introduction}

In the last few decades, there has been a rapid development of industries in South Asian countries. One main driving force for the phenomena has been low cost of labors in developing countries. For this reason, many foreign companies shifted their manufacturing centers to developing countries. Most of the workers are engaged in rather simple jobs in which no specialized abilities are required (Copps \& Plimmer, 2013). This process commonly happened in the first stage of industrialization of developing countries. The need for large numbers of low cost workers has been an advantage for highly populated South Asian countries. In the next stage of the industrialization, however, welleducated good quality workers with specialized abilities are required. These people are expected to play important roles in developing their industries further in their own way. The point is the improvement of the higher education systems so that they can produce workers who have enough abilities for performing leadership in the higher stages of industrialization.

The academic staffs of higher education sectors in South Asian countries are making continuous efforts to improve their research and educational activities so that they suit for the requirements of various industrial sectors. In order to assist this, the authors have been working for the KISSEL project (Warnajith et al., 2012). The KISSEL stands for Knowledge Integration Servers System for ELearning. It is a web portal network for teachers and researchers in Asia and Pacific countries. It works as a communication platform where they can share the knowledge and experiences of improving education methods with the aid of Information and Communication Techniques (ICT). This paper summarizes the planning and the practice of KISSEL project that has been carried 
out in the last ten years. As a result, it makes clear the future problems that could be solved with the aid of ICT. The strategy of the second phase of the KISSEL project is also noted in relation to the future problems.

\section{Research and Education by Means of ICT}

In the long history of South Asian countries, a considerable amount of knowledge has been successfully accumulated in various fields of natural, social and human sciences. They have established suitable research methods for studying individual topics of sciences, which are now called "traditional methods" in this paper. If the traditional methods are combined with the latest ICT, new powerful scientific approaches can be established. Eresearch refers to the use of advanced ICTs to support research. E-research aims to ensure research processes are more effective, efficient and collaborative. Let us show this in the following examples of KISSEL contents: i.e., environmental science, Sri Lankan archaeology, social and cognitive psychology, and language education.

\section{Environmental Science and ICT}

ICTs such as satellites, mobile phones or the Internet play a key role in addressing the major challenges related to environmental science including climate change and sustainable development. ICTs are fundamental for monitoring climate change, mitigating and adapting to its effects and assisting in the transition towards a green and circular economy. Further, environmental benefits of ICT applications are evident in areas such as water management, biodiversity protection, pollution reduction and preparedness of climatic change impacts including global warming etc. Applications on ICT related to environmental science in South Asian countries, seem to be meager, which is the one of the key interest areas of the authors. 
Currently, South Asian countries are rapidly experiencing fast economic growth, which often causes considerable environmental changes. Therefore, environmental considerations are taken into account in all spheres of economic development in the region. ICT can be integrated in long-term studies, both retrospective and predictive, in order to anticipate degradation and to take mitigating measures at an early stage. It is also imperative to collect and integrate data from different disciplines. These are essential in the spirit of sustainable development and management, particularly in developing countries, which are often more vulnerable to environmental degradation.

To increase awareness on environment-related problems among the general public including students, researchers, academics and policymakers, ICT can be used as an efficient and effective tool for education. By raising awareness on the role of ICTs, KISSEL is promoting transformative solutions for environmental science that can ensure a sustainable future for South Asian Countries. All the research findings should be easily accessible and presented in a user-friendly manner. Further, these research data in the form of electronic media can be easily used in education of or training in environmental science. Therefore, development of a database on the water environment of Asian countries on KISSEL server system was initiated, for the benefit of all interest groups including the general public (Dahanayaka et al., 2015).

This sector describes application on Remote Sensing Research on water environments on KISSEL, which were used as multimedia data sharing platform for benefit of several stake holders especially in Asia. We already developed Sri Lankan Coastal Water Body Database (CWBDS) (Figure 1), Asian Water Environment Database (AsiaWED) and Satellite-based Lake and Reservoir Temperature Database (SatLARTD) on KISSEL server system based on Remote Sensing Studies, and presently it contains water quality data of lakes, reservoirs, lagoons and estuaries for over three decades (Dahanayaka et al., 2013; Dahanayaka et al., 2012a; Dahanayaka et al., 2012b; Dahanayaka et al., 2011). To develop databases, research works parallel to satellite overpass were conducted on 
selected Asian water environments considering its economic and ecological importance.

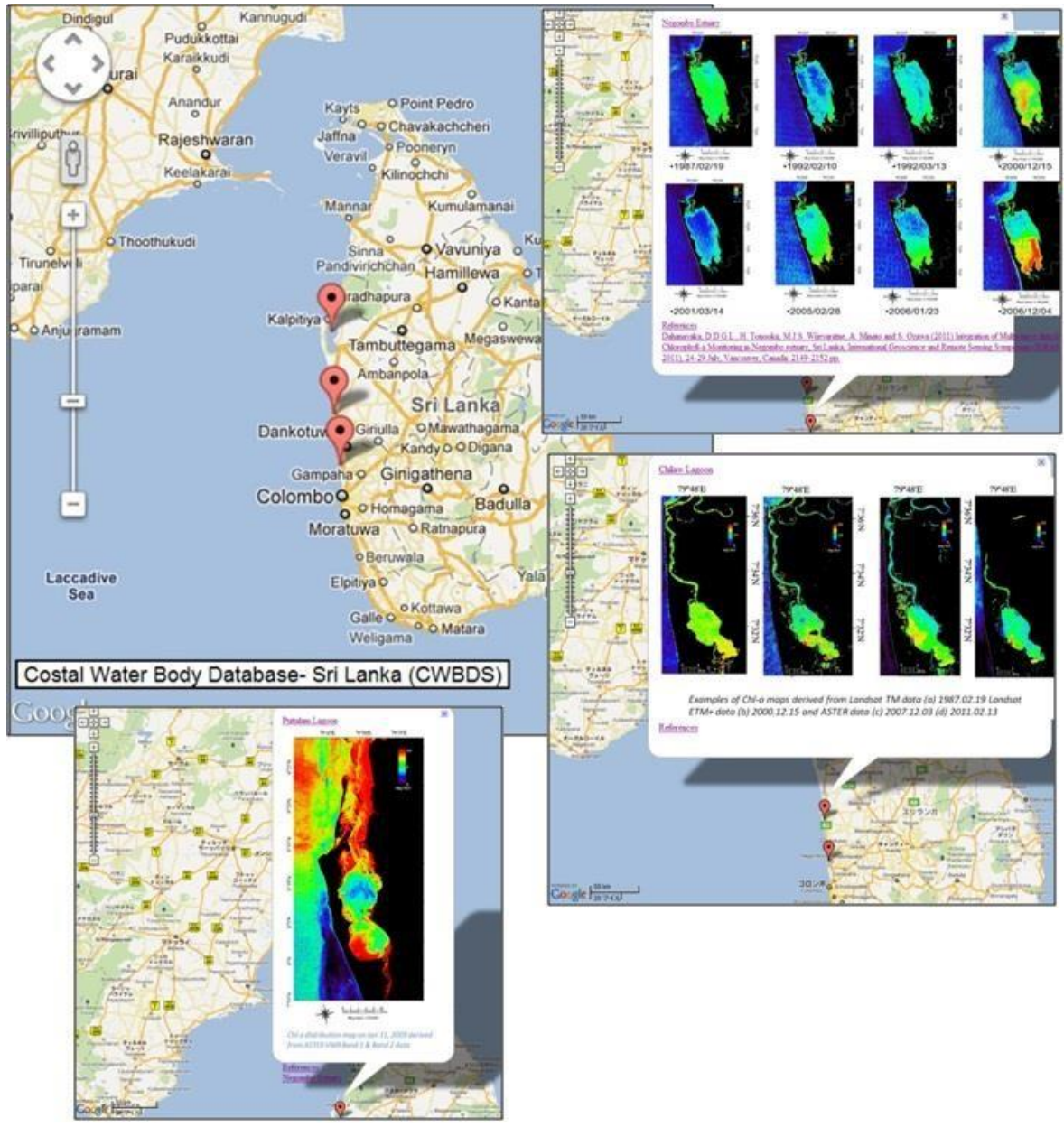

Figure 1. Coastal Water Body Database (CWBDS) of KISSEL showing Chlorophyll-a distribution in selected estuaries and lagoons of Sri Lanka

Local Universities and/or Research Institutes collaborated in field data collection, and in future continuous monitoring programs of water bodies and KISSEL-related activities. Combination of remote sensing and the traditional method (field work method) can be used as a powerful research method by using data that is uploaded to KISSEL. 
Monitoring long term changes of water quality and land use changes using satellite data, improvements of water body databases and deriving of future predictions and recommendations will be conducted. At present, the contents related to environmental science of the KISSEL are concerned to use as E-learning techniques and early warning preparedness and mitigation of natural disasters.

KISSEL is an e-Learning platform for South Asian countries where teachers and researchers of this region can share their knowledge and collaborate in education and research activities in order to face the challenges of the rapidly changing natural environment. The databases will useful for their future academic and research activities. Further, these research data in the form of electronic media can be easily used in education of or training in environmental science. Workshops, seminars, conferences and field work trainings on environmental science education have been carried out in the member countries by the members of the KISSEL group and following can be highlighted among them.

Research work on environmental monitoring of Taal Lake, Tagaitai and Manila, Philippines, 28th February - 2nd March \& 8th - 12th March 2014.

Research work on environmental monitoring of Musi River and conducting guest lecture (Sriwijaya University, Palembang), Indonesia, 02nd -08th March 2014.

Workshop on long-Term Monitoring of Mangrove Ecosystems Response to Climate Change, University of Science, Ho Chi Minh City, Vietnam, 10-11 October 2013.

Research work on environmental monitoring of inland water bodies, Hanoi, Vietnam, 23 - 27 May 2013

Introductory lectures on KISSEL server system at the Kathmandu University, Nepal, 18-21 August 2012.

Introductory lectures on KISSEL server system at National University of Science, Ho Chi Minh City, Vietnam, 07-12 April 2012.

KISSEL Technical Seminar- 2015, Ibaraki University, Japan, 20-23, Mar 2015.

International Symposium on ICT for Environmental Sustainability (ICTES 2014) - University of Kelaniya, Sri Lanka, 23-25, Jun 2014. 
KISSEL Technical Seminar- 2014, Ibaraki University, Japan, 17-19, Feb 2014.

International Symposium on Sustainability Science and ICT (ISSSICT 2012), Ibaraki University, Japan, 26-28, March 2012.

International Symposium on ICT for Sustainable Development 2016 (ICTSD 2016), University of Kelaniya, Sri Lanka, pp. 11, 10-12 August 2016.

\section{Sri Lankan Archaeology and ICT}

Over the last two decades, there have been significant efforts in various fields of archaeology for improving the research methods with the aid of ICT. The new approach of using computer for the analysis of conventional archaeological data by developing specially designed computer applications is known as "computational archaeology", of which examples are 3D modeling in archaeology (López et al., 2016), satellite remote sensing (Tapete \& Donoghue, 2012), GIS applications (Duke \& King, 2012), and writer recognition of inscriptions (Panagopoulos et al., 2009). Sri Lanka is fortunate because of the richness and the diversity of remaining archaeological artifacts. Among the archaeological written resources, inscriptions have inestimable value because they are contemporaneous unlike most of the literary sources. This subsection summarizes points of a computational archaeology study applied to Sri Lankan inscriptions in the last few years (Bandara et al., 2012).

Up to present, estampage has been a main and popular copying method of inscriptions in Sri Lanka. This method comprises the following steps: (1) putting some water on to the inscription and laying a special paper on it (2) chopping on the paper, until the shapes of letters are engraved on the paper (3) putting ink on the paper, and rubbing the surface of the paper with a piece of cloth with ink, letting the paper dry to some extent, and (4) removing the paper from the stone. Some of important inscription data have been digitized and are stored in the KISSEL system together with the developed ICT technique for analysis. It is shown there that application of computer pattern recognition technique is useful for 
studying the inscriptions of Sri Lankan Brahmi letters. The digitized inscription data, new analysis method and new findings are being shared with many researchers through KISSEL communications. In the following section, let us show an example of the analysis of estampage by means of a computer.

The source data of the analysis are grayscale photo images of inscriptions (Perera, 1964) shown in Figure 2. They are a part of the paper copies of inscription estampages. Firstly, the standard shape of each Brahmi letter alphabet would be decided as follows:

1) scanning and separating of sample letter images, 2) binary coding ( 0,1 or white and black coding) of each letter image, 3) removing noises from the letter images, and 4) determining the standard shape of alphabet of Brahmi letters from a lot of estampage data and the computer analysis based on majority algorithm (Bandara et al., 2012). Figure 3 shows binary images of the inscription letters: (a) before and (b) after nose reduction processes by computer.

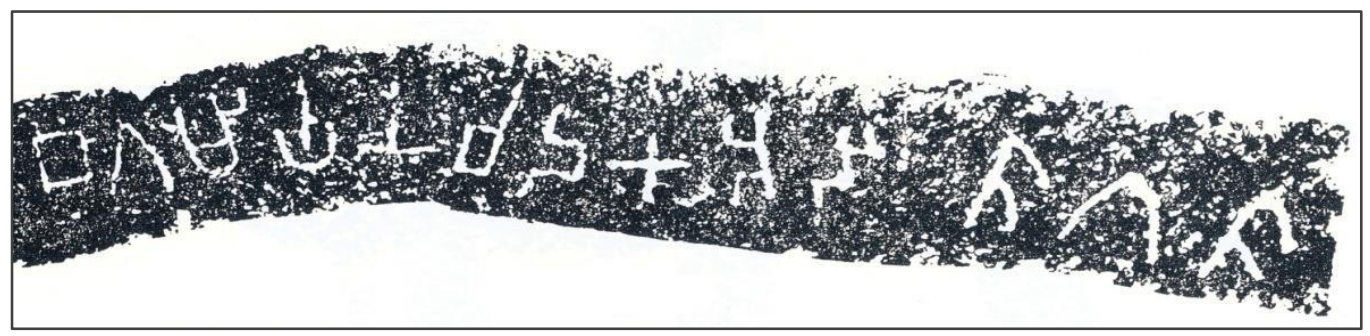

Figure 2. Photo image of original inscription found in Nācciyārmalai area in Trincomale district, Eastern province, Sri Lanka (Paranavitana, 1970) 


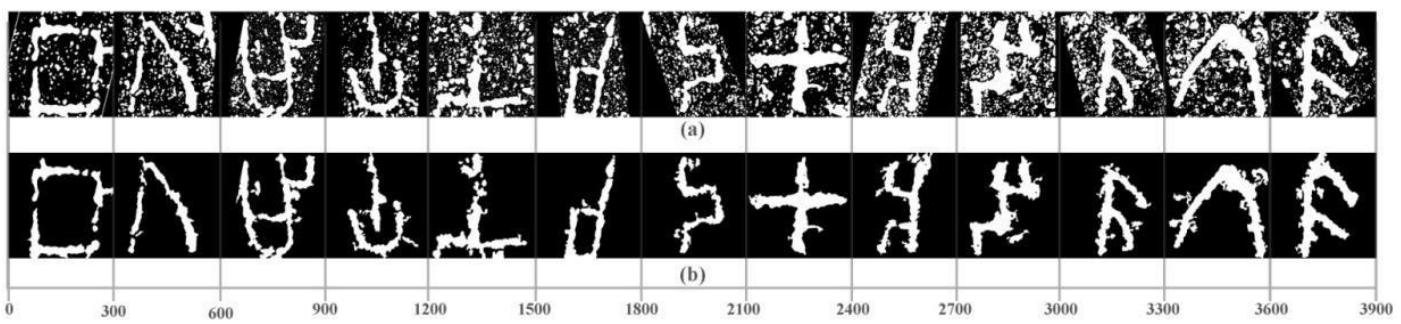

Figure 3. Two kinds of processed inscription images (a) with noises, (b) without major isolated noises. Here, the horizontal position is shown in units of the pixel numbers along the images

Once the standard shape of each Brahmi alphabet is decided in the form of "standard Brahmi letter fonts", automatic identification of Brahmi letters of inscription is possible by studying correlation between sample image and the font image by computer. This opens the way to semi-automatic analysis of huge amount of data stored in the form of estampages. Authors have started to produce digital data repository of Sri Lankan ancient letters on KISSEL where the traditional estampage data, computationally processed images, and other important information such as place of the inscription, latitude-longitude data, the text expressed by standard fonts, meaning of the text, period, literature references, etc. are included. The KISSEL is a completely open system. The digital repository data can be used freely by researchers, teachers and also students of South Asian countries. If the study is carried out in such a way, i.e., internationally with the aid of ICT, it will be not so long before we can fully understand the development of South Asian languages in their historical contexts.

\section{Social Decision-making Process and ICT}

Decision-making can be regarded as the psychological processes (cognitive process) resulting in selection of a course of action among several alternative scenarios. Every decision-making process produces a final choice (Reason, 1990). According to Wang \& Wang (2004), decision making is one of the fundamental 
cognitive processes of human beings that is widely used in determining rational, heuristic, and intuitive selections complex scientific, engineering, economical, and management situations, as well as in almost each procedure of daily life. Since decision making is a basic psychological process, it occurs every few seconds in the thinking courses of human mind consciously or subconsciously (Wang \& Ruhe, 2007). Some of the decisions we make every day are personal decisions and the others are social. An example of personal decision making is to decide what to take for lunch or how to spend the weekend. An example of social decision making is to decide on a future energy source for producing electricity. It can be nuclear energy plant or some sort of renewable sources such as solar energy plant. Both personal and social decision making are quite complicated processes and stochastic in nature. In social decision making, various messages are exchanged among people, which influence their ideas. In personal decision making, various ideas come to our minds and a kind of negotiation occurs between them. This process is nothing but "talking" in our mind, or internal message transfer. In communication studies, this process is called "intrapersonal communication" (Luria, 1961). We can understand that even though the personal and social decision making differ in their dynamics, both types of decision making have a similar mechanism which is based on message exchange, i.e., message formation and message transfer.

The basic sciences related to decision making are cognitive psychology and social psychology (Anderson, 1981). Emotional factors sometimes play an important role even in rational decision making. The basis of any decision making is knowledge regarding the given problem, namely information about the problem obtained before. This is true for emotional decision making as well as for rational decision making. Here, we try to express the decision-making process in a society in terms of mathematics. With this, we focus our attention on application of computer simulation method for studying the decision-making processes in a society. Here the key issues are articulating knowledge and creating and exchanging of messages through mathematical 
functions. It should be noted that knowledge and messages to be expressed mathematically are only those which are related to the given problem that is to be studied.

In order to carry out the computer simulation, a multi-agent artificial society model was proposed. In general, an artificial society is a synthetic representation of a society (Epstein \& Axtell, 1996). It consists of agents, which act in an environment by following given rules. According to the standard terminology, an artificial society is a particular case of the so-called agent-based models. Such models address 'possible societies', their general processes, dynamics, and emergent properties (Gilbert \& Conte, 1995). Such artificial society models could be very useful tools to analyze and understand social processes as Hales (1998) noted. He says that the aim of artificial society modeling is to model features and processes which characterize societies in general: cooperation, specialization, group formation, hierarchy etc. Artificial society work does not strive for superficial realism or direct correspondence with existing societies but for abstract logical relationships that characterize whole categories of phenomena. Figure 4 illustrates the artificial society model in general.

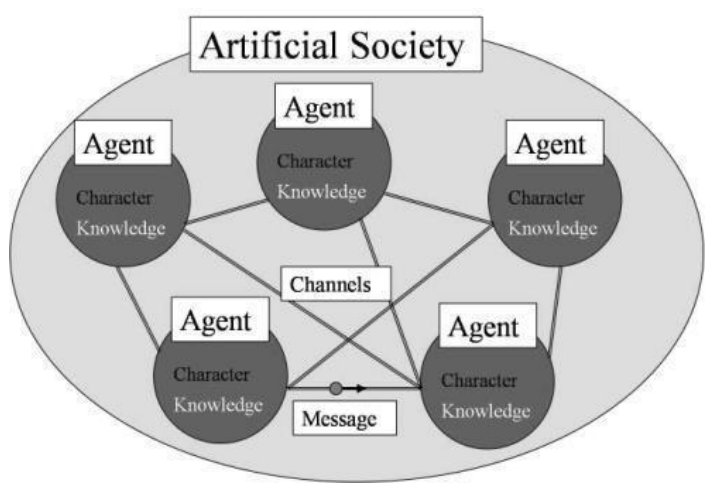

Figure 4. Artificial society model regarding 'a given problem' which is used for mathematical formulation in the decision-making processes of a society. 
The model that we propose, namely psychology-oriented artificial society model, provides an algorithm of computer simulation for the decision-making process in a society. In order to formulate a mathematical formulation for the personal decision making it was necessary to create an algorithm and a linkage model of cognitive psychology (Weiner, 1980). The model was implemented to analyze the decision-making process in Bangladesh regarding the acceptance of nuclear power plants. More details of the model and its application can be found in Quarmal et al., (2012a), Quarmal et al., (2012b), and Quarmal \& Ozawa (2013).

Programming language $\mathrm{C}$ together with a graphics tool, SGLSimple Graphics Library (Ozawa et. al., 2010), has been used in the program code of the computer simulation. Also, a web-based tool titled "Keyword Extractor" was developed to assist the process of computer simulation of social decision-making process using the psychology-oriented artificial society model, which was freely accessible through the KISSEL website.

Computer simulation method for psychology could be a very effective tool to understand social trend for (1) psychological phenomena that can be described quantitatively (2) dynamics of the psychological phenomena that can be described scientifically by modeling the process occurring inside of human brain (3) forecasting future results of psychological phenomena.) By changing the parameters of the model, it is possible to study the phenomena for various situations.

\section{Language Education and ICT}

ICT Language laboratory systems are popularly used in public schools, language schools and also in university-level education. Many commercial packages for various methods of language education have already been distributed all over the world. In this paper, one special problem in language education was studied. The Ritsumeikan University group of KISSEL project noted the importance of mother tongue education for young children of foreign workers who live only few years in foreign countries (Ozawa, 2013). Young children of foreign workers, for example in Japan, quickly master the Japanese language, but they are 
usually cut off from the environment of their mother tongue. After coming back to their country of origin, they have difficulties in adjusting to the language and culture at home. Special E-learning materials have been developed for such persons and were opened to the public in the form of E-books via KISSEL. The E-book library of KISSEL contains libraries of English-Japanese, ChineseJapanese, Spanish-Japanese, Portuguese-Japanese, TagalogJapanese and Japanese (KISSEL, 2017). The contents of each library could be further classified into three categories: Storybook, Flashcard (small E-book of few MBs) and Vocabulary book (E-book for expanding one's vocabulary). These are multimedia type E-learning materials in Daisy format and a special browser AMIS is used to open the Daisy file. The users are requested to 1) get AMIS from http://www.daisy.org/amis/download, 2) download an aimed Ebook file from the libraries in KISSEL contents and unzip the file, and 3) open the initial page (ncc.html) by AMIS. In each library, several storybooks are included of which topics are selected for young children. When the E-book is opened, recorded voice of reading appears together with illustrations and texts of the story in two languages. Figure 5 illustrates one page of the E-book. This example is taken from a storybook in the English-Japanese Daisy library. Japanese sentences and corresponding English sentences are printed there. The both sentences are read in sequence. The shade bar on the text shows the textual location of that is being read.

The Ritsumeikan University group of the DAISY project is engaged in volunteer work of language education for young children of foreign workers in Japan (Ozawa, 2013). They organize small language classrooms in local societies. The students of the university work as illustrators of the classes. This example shows that E-learning method is suited for education of selected group of peoples. It is noted that the same technique can be applied to the education of refugees or immigrants who are cut off from the language and the culture of their mother countries. The authors are planning to include this topic into the next phase of KISSEL project with the aid of mobile learning technique (Ozawa \& Ualesi, 2017). 


\section{いろいろなホットケーキ}

Make different kinds of pancakes

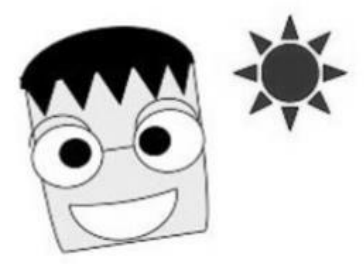

いろんなホットケーキをつってたのしもゔ。いろいろなたちにつくるよ。

Let's make different kinds of pancakes. We can make various types of pancakes.

\section{みぎのは、おおきいホットケーキ}

The one on the right is a big pancake.

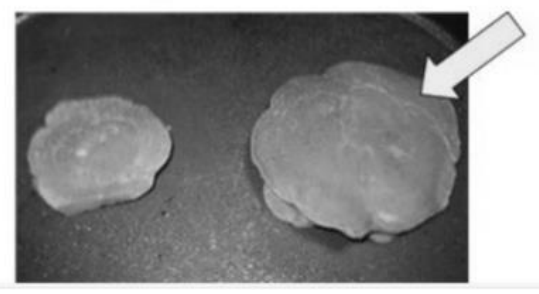

Figure 5. A page of an E-book taken from Daisy library in KISSEL

\section{Emergent Digital Culture}

We live in the age of information. Hardly any sector can be found where ICT does not have strong impacts, be it communication, business, education, agriculture, medicine, entertainment or any other sector. As such, rapid changes triggered by ICT can be observed everywhere, even in developing countries like Bangladesh where the number of people having access to ICT is really low. Considering this, KISSEL group in Bangladesh is working on exploring the ICT impacts in different sectors as well as in people's lives. One such study on "Mobile Phone as Parenting Device in Dhaka City" (Khan \& Quarmal, 2015) explored the usage of mobile phone as a parenting device in Dhaka City and its impact 
on parenting. The study revealed that mobile phone has become an inseparable part of life in Bangladesh. Parents of teenage children in Dhaka City are nowadays providing mobile phones to their children that they could track their where about, get updates and provide directives to them. However, its use as a parenting device is not yet mastered by the parents in Dhaka City because as 'digital immigrants' they are not well acquainted with all the features mobile phones such as surveillance features. On the other hand, providing teenagers with mobile phones can be really harmful as the parents cannot fully control the usage of mobile phones by teenagers.

In another study entitled "Role of Social Media in Shaping Communication Behavior of Urban Youth in Bangladesh", Quarmal \& Osmani (2015) have analyzed the role the social media play in shaping communication patterns and behavior of the urban youth in Bangladesh and the factors that contribute to this process. In this study, over 300 young adults were surveyed in three cities (Dhaka, Rajshahi \& Barishal) across the country. To gain more insight out of the survey, academics were interviewed as well. The study revealed that social media has become a part and parcel of the lives of young people in the country. They spend a significant amount of time (about one-fifth of the day) in social media and some of them literally live 'online'. Social media has become such an integral part of their lives that unavailability of access to social media makes them 'feel lost' even 'crazy'. Nowadays, they use social media not just for communicating with distant friends and relations; they use it for communicating with near-by people as well. They also use social media extensively for education and entertainment. Such extensive usage of social media affects the pattern of youth's day-to-day communication in physical spaces as well; the findings show that their interactiontime with people in physical spaces such as hanging out with friends, visiting family and relatives, is much lesser than that in the virtual space. The study revealed that one of the most important reasons behind such popularity of social media as a communication platform among the Bangladeshi youth is the convenience of time and space, especially in Dhaka where physical 
mobility is highly challenged due to bad traffic and lack of public transport. Also, many of the respondents from Dhaka mentioned that due to the dearth of spaces for outdoor sports and other social interactions, they prefer to spend time and interact with other people using social media even though many of them "miss the warmth of face to face interaction". The study revealed that, the young people in Dhaka city are more dependent on social media for their day to day communication than the youth living in the other two cities. Their interaction with friends, family and relatives in physical spaces is much lesser than that in the other two cities as well.

The experts who were interviewed during the study also reflected on the social media usage of young people, they agreed that it seems a double-edged sword. On the one hand, it opens up opportunities for easy and convenient communication around the globe, provides a channel for education and entertainment, creates a discursive space for expressing opinions on different issues, and creates a 'comfort zone'. But, on the other hand, the experts say that extensive use of social media could lead to lack of interaction in physical spaces and that could negatively affect communication skills. Extensive use of social media may have some negative effects; many might think of putting a bar on their children's social media activities. According to the experts, that's not the proper way to deal with it. One of them, a practicing psychologist, recommended the creation of a 'healthy' environment in the family by providing young people a sense of belonging and quality family time; they should be allowed to use social media but should be discouraged from finding an 'escape zone' in it.

Undoubtedly, a digital culture is emerging globally and ICT has become an integral part of life and is making an impact on the way people live their lives on a day-to-day basis; the way they connect with the people surrounding them; the way they undertake activities such as governance, health, commerce, agriculture, education, etc. As such, it is important to explore the trends in this emergent digital culture. Having similar eco-social-cultural 
realities, the above-mentioned studies are important for other South Asian countries. Researchers in those countries may undertake similar work which may help the general public as well as the policy-makers with the notion of the proper utilization of ICT.

\section{Discussion}

As suggested in above discussion, new powerful scientific approaches can be established by combining the traditional methods with the latest ICT. The merits of the new research methods of using ICT are:

1) Analog data (for example, printed data of estampages (Bandara et al., 2012) are converted in to digital. Digital data can be easily processed by a computer. As a result, the process of data analysis becomes speedy and precise, free from human error. Sometimes semi-automatic data analysis is available with the aid of computer programing.

) The digital data is easily distributed to other people through networks or via electronic media. This is convenient for people in distant places to carry out research or educational collaborations.

3) The systematic management of huge amount of scientific data accumulated becomes available through the usage of the database technique. Various data analysis methods, for example, taking correlation between different data can be applied to the database.

4) Most of the scientific data are numerical. Once the data is fed to the computer, such data can be represented in different ways by using various graphic tools. This process helps to understand the meaning of the data.

5) Theoretical modeling combined with computer simulation can be a powerful method for studying complicated natural or human systems. It is sometime possible to forecast future states of the system from knowledge parameters of the initial condition. 
The new ICT approaches not only improve the traditional research methods but also produce good effects on educational activities because the fruits of research can be easily integrated into education as far as the education is also carried out through an ICT method. The results of researches stored on KISSEL servers can be used as educational materials for schools and universities. In this sense, E-learning and E-research are important. Students should master such abilities to handle the new ICT approaches.

Here it is worthwhile to note that the primary ability that is required by today's industries is the application of specialized knowledge by means of ICT. If high education systems are upgraded this way, industrialization in South Asian countries will grow. Actually, a considerable amount of effort is already divested in ICT education in South Asian countries. Authors are aware of the connection between academic and industrial sectors in South Asian countries. If highly educated people are not employed in industries, it raises serious issues. In the Japanese society, a seamless connection is established between educational sectors and industrial sectors. Most of university students find their jobs before graduation. There are social rules and well-established system for various recruiting activities in Japan. Each university has a recruiting center that takes care of student's job hunting. Many companies adopt internship methods that provide opportunities for students to experience working in the company before they graduate from a university. In order to realize such seamless connection between academic and industrial sectors in South Asian countries, a considerable amount of efforts must be invested. Here, ICT may be a useful tool for improving the connectivity between the academic and industrial sectors. This can be one of the main targets for the next stage of the KISSEL project. The details will be reported elsewhere.

\section{Conclusions}

The present paper discussed how a scientific project, based on an ICT platform, helped and could continue to help researchers to collaborate and share knowledge. In South Asian countries, the 
continuing efforts are needed for the innovations of research and educational methods by means of the latest ICT. In order to carry out the innovations efficiently, communications between researchers and/or teachers are important. The KISSEL system is so designed that they can share ideas, knowledge, experience, technique that are needed for innovation. One common problem in South Asian countries is that they do not have seamless connectivity between the educational and industrial sectors. The problem should be solved in collaboration with various researchers and/or teachers in South Asia. The KISSEL system will support such future collaborations.

\section{Acknowledgements}

A part of this work was supported by Grand-in-Aid for Scientific Research (C) 2008 No.20500825 and Grand-in-Aid for Scientific Research (B) 2012 No.24300278. The KISSEL project originates in previous research cooperation with the Sri Lankan researcher Dr. Gamunu Dassanayake and Samoan researcher Dr. Vaise Patu while they were working for their doctoral thesis at Ibaraki University.

\section{References}

Anderson, J. R. (1981). Identification of Common Molecular Subsequences. San Francisco: W.H. Freeman.

Bandara, D., Warnajith, N., Minato, A., \& Ozawa, S. (2012). Creation of precise alphabet fonts of early Brahmi script from photographic data of ancient Sri Lankan inscriptions, Canadian Journal on Artificial Intelligence, Machine Learning and Pattern Recognition,3(3): 33-39.

Benenson, I., \& Torrens, P. (2004). Geosimulation: AutomataBased Modeling of Urban Phenomena. UK: John Wiley \& Sons Ltd.Copps, J. and Plimmer, D. (2013). The journey to employment. A guide to understandingand measuring what matters for young people. Featuring the Journey to Employment(JET) framework, New Philanthropy Capital. 
Dahanayaka, D.D.G.L., Quarmal, S.B., Warnajith, K.N.S., Dassanayake, G., Tonooka, H., Minato, A., \& Ozawa, S. (2015). Expansion of the Remote Sensing Research on water environments of Asia through KISSEL Server System, ICT for Development Working Paper Series, 5 (1): 54-63.

Dahanayaka, D.D.G.L., Tonooka, H., Wijeyaratne, M.J.S., Minato, A., \& Ozawa, S. (2013). Two decadal trends of surface chlorophyll-a concentrations in tropical lagoon environments in Sri Lanka using satellite and in-situ data, Asian Journal of Geoinformatics, 13 (3): 15-25.

Dahanayaka, D.D.G.L., Tonooka, H., Wijeyaratne, M.J.S., Minato, A., \& Ozawa, S. (2012a). Monitoring Land Use Changes and their Impacts on the Productivity of Negombo Estuary, Sri Lanka Using Time Series Satellite Data, Asian Fisheries Science 25: 97-212.

Dahanayaka, D.D.G.L., Tonooka, H., Wijeyaratne, M.J.S., Minato, A., \& Ozawa, S. (2012b). Development of Coastal Water Body Database on KISSEL Server, 11th International conference on Information Technology Based Higher Education and Training (ITHET 2012), Istanbul, Turkey.

Dahanayaka, D.D.G.L., Tonooka, H., Wijeyaratne, M.J.S., Minato, A., \& Ozawa, S. (2011). Evaluation of Chlorophyll retrieval algorithm using an intermittently closed tidal estuary: The Chilaw lagoon in the west coast of Sri Lanka, Proceedings of the $51^{\text {st }}$ Conference of the Remote Sensing Society of Japan (RSSJ), pp. 55-56.

Duke, D., \& King, J. (2014). A GIS model for predicting wetland habitat in the Great Basin at the Pleistocene-Holocene transition and implications for Paleoindian archaeology, Journal of Archaeological Science, 49: 276-291.

Epstein, J. M., \& Axtell R. (1996). Growing Artificial Societies: Social Science from the Bottom Up. Washington DC: Brookings Institution Press.

Gilbert, N., \& Conte, R., (1995). Artificial Societies: The Computer Simulation of Social Life. Taylor \& Francis. 
Hales, D., (1998). Artificial Societies Theory Building and Memetics. 15th International Congress on Cybernetics NAMUR (Belgium). August 24-28, 1998.

Home page of KISSEL:

http://kissel.base.ibaraki.ac.jp/intl/index.php

James Reason (1990). Human Error. Cambridge University Press

Khan, H. K., \& Quarmal, S. B. (2015). Mobile Phone as Parenting Device in Dhaka City. ICT for Development Working Paper Series, 5(2): 36-52.

López, J.A.B, Jiménez, G.A., Romero, M.S., García, E.A., Martín, S. F., Medina, A.L., \& Guerrero, J.A.E. (2016). 3D modelling in archaeology: The application of Structure from Motion methods to the study of the megalithic necropolis of Panoria (Granada, Spain), Journal of Archaeological Science: Reports 10: 495-506.

Luria, A. R. (1961). The role of speech in the regulation of normal and abnormal behavior. J. Tizard(ed.). New York: Liveright.

Ozawa, S., \& Ualesi, E.T. (2017) Mobile Learning, Chap. X: A pilot Study of Mobile Learning in Higher Education in Samoa, Springer-Verlag, Germany, in press (to appear in April 2017).

Ozawa, W. (2013). Action Research to build a Transnational Volunteer Support Network for Foreign Students' Education: Possibility of Digital Book System as a Tool for Volunteer Linkage, ISTR, Asia \& Pacific Regional Conference, Seoul.

Ozawa, S, Joarder, M. A., Dassanayake, G., \& Patu V. (2010). Introduction to $\mathrm{C}$ and $\mathrm{X}$ Window Programming. Colombo: Godage International.

Panagopoulos, M., Papaodysseus, C., Roussopoulos, P., Dafi, D., \& Tracy, S. (2009). Automatic writer identification of ancient Greek inscriptions, IEEE Transactions on Pattern Analysis and Machine Intelligence, 31(8): 1404-1414. 
Paranavitana, S. (1970). Inscriptions of Ceylon, Department of Archaeology, Colombo, Sri Lanka.

Perera, L.S. (1964). Lanka Ithihasaye Muulashra, Journal of Sri Lankan History, Vidyalankara university Sri Lanka, vol 1: pp 47.

Quarmal, S. B., \& Osmani, M. H. (2015). Role of Social Media in Shaping the Communication Behavior of Urban Youth. ICT for Development Working Paper Series, 5 (2): 53-68.

Quarmal, S. B., \& Ozawa, S. (2013). Acceptance of ICT-Enabled Services among Bangladeshi Farmers, ICT for Development Working Paper Series, 3(2): 20-40.

Quarmal, S. B., Kamal, M. K., Afroj, S., Warnajith, N., Amin, M. R., Itaba, M., Minato, A., \& Ozawa, S. (2012). Study of decision making process using psychology-oriented artificial society model, Part 2: Analysis of decision making process in Bangladesh regarding the acceptance of nuclear power plants, International Journal of Computational Engineering Research, 3(1): 116-124.

Quarmal, S. B., Itaba, M., Minato, A., \& Ozawa, S. (2012). Study of Decision Making Process using Psychology-Oriented Artificial Society Model, Part 1: Proposal of Mathematical Formulation for Computer Simulations of Psychology. Canadian Journal on Artificial Intelligence, Machine Learning and Pattern Recognition,3(1): 14-23.

Tapete, D., \& Donoghue, D. (2012). Satellite Remote Sensing: A New Tool for Archaeology by Rosa Lasaponara and Nicola Masini (eds). Springer-Verlag, Heidelberg.

Wang, Y., \& Ruhe, G. (2007). The Cognitive Process of Decision Making. International Journal of Cognitive Informatics and Natural Intelligence, 1(2): 73-85.

Wang, Y., \& Wang, Y. (2004). Cognitive informatics models of the brain. IEEE Transactions on Systems, Man, and Cybernetics (C), 36(2): 203-207. 
Warnajith, N., Quarmal, S.B., Itaba, M., Minato, A., \& Ozawa, S. (2012). Formation of knowledge sharing system for Asia Pacific countries by using modern information techniques, International Journal of Computational Engineering Research (IJCER), 2(7): 204-211.

Weiner, B. A. (1980). Cognitive (attribution)-emotion-action model of motivated behavior, Journal of Personality and Social Psychology, 39(2): 186-200. 